\section{HISTÓRIA, EDUCAÇÃO E CIDADANIA}

\author{
Margarita Barretto'
}

RISL:MO: O Turismo pode scr uma eveclente "ferramenta" pedagigica a serviço do ensino de História c (ieogralia. Ncsse sentido, relatam-sc o desenvolvimento e a aplicacaa oxpcrimental dc unn projeto com cssa proposta. demonstrando a viabilidade dal rcalizaçào dc "city touıs" especializados $\mathrm{cm}$ História do Município de (ampinas. () projecto baseia-se. de un lado. nas icorias de cducação da cscola ativa c. Je out ro. no estudo das raizes históricas do Turismo. () qual foi. antes de uma proposta de lazcr. uma proposta educativa.

PAl.aVRas-( HIAVI: Turismo: cducação: histơria. Turismo cultural turismo cducativo: turismo histórico.

ABSTRACT: It ispossible to link Tentism and l:duc ation, mainh in I/ iston.

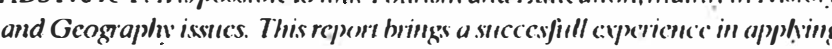

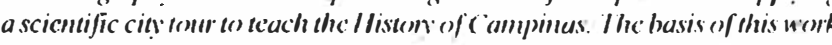
arc, by one side in the "learn-by-dening" theorics of cducation and, by the other. in the belict that Tourism begent as an edecational propossul, becoming a lcisure matuer onh in this centurn

KEY WORIDS: Tourism: cducatiom; histony: (ultural tentrism: celucatumal tourisin; historical tomism.

\section{INTRODUÇĀOO}

Este artigo cnfoca um projeto pedagógico oriundo de uma proposta de turismo cultural, cuja aplicaçáo experimental permitiu verificar a viabilidade de se ensinar História através de um dos aspectos do receptivo, o "city tour".

Nesse sentido, apresenta-sc, inicialmentc, a rclaçāo Turismo/Educação, destacando a cvoluçáo do conccilo de turismo c a função cducat iva presente nas viagens turísticas, desde o século XVI. Fa\%-sc, depois, um

1 Bacharel cm Turismo e Pósgraduanda da laculdade uc I:ducação da LiNICAMP . Universidade de Campinas. Professora da Faculdade llocro-Americana $e$ Coordenadora da "Coleção T'urismo" da l idilora P'apiruis.

End. para corresp.: R. José Aparccido Pavan. 6,50 - Parque das Liniversidades 13086-080 - Campinas - SP - Brasil. resumo de importantes teorias pedagógicas, destacando o ensino da História através dos chamados "sitc muscums" (muscus no locial)

A partir dessas colocaçocs, disculc-sc o projelo lïrende) a Hislório de Campinas, cuja relevância decorre da importância com que họ̣c se revestem as questõcs da memória cultural. Na medida cm que a Hisiória é melhor apreendida pela possibilidade de vivéncia dada pelo Turismo, sāo maiores as chances de criar um verdadciro sentimento de cidadania nos alunos participantes.

\section{TURISMO E EDUCAÇÃ()}

\subsection{Conceituação}

Procurar as raizes da palavra turismo leva nada menos que à Biblia, de acordo com o autor Arthur Haulot que, em 19(1), escreve sobre a possibilidade da origem hebraica da palavra "tour". "Tur" cm hebraico antigo aparece no livro dos Númcros, cap. XII, vers. 17, cm que Moisés envia um grupo de representantes a Canaā para visitá-Ios. Nessec contexto a palavra "tur" quer dizer "viajem de descoberta" (FERNANDEZ FUSTER, 1974:22).

Modernamente, em 1746, surge a frase "to lake a turn", na Inglatcra que, influenciada pelo francês, em 17(s), transforma-sc $\mathrm{cm}$ "to make a tour" (FERNANDEZ FUSTER, 1974:2(1)). A partir daí, diversos estudiosos de turismo registram várias definiçôes, que enfatizam aspectos diferentes conforme as ćpocas.

Hoje há um consenso de que a abrangência secial do turismo é irredutível a uma só catcgoria. A sua peculiaridade reside, justamente, em abranger aspectos econômicos, psicológicos, sociológicios c técnicos; é um fenômeno polifacético que só pode scer estudado com um processo de interação social. Dois clementos, no entanto, esitio presentes na maioria das suas definiçōes: a intencionalidade e a linalidade recreativa. A definição de Toroisi abrange o aspecto intelectual:

Turismo é o conjunto de traslades temperrais de pessous por neccssidade de reponso cura ou imelectiais. (FERNANDL:\%. IUS7I:R. 1974:27)

Por outro lado, o turismo

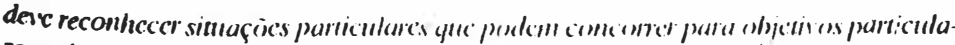

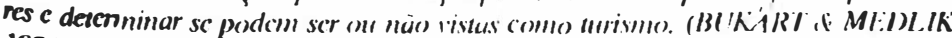
1974:4(1)) 
Assim, neste artigo entende-se turismo como movimento de pessoas para fora do seu local de residência, e fenômeno furístico como todas as causas e conseqüências desse deslocamento, formando um sistema de relaçōes sociais e econômicas. Propōe-se que scja classificado como seniço turístico um passcio que se utiliza de um equipamento (o transporte) e de um serviço pessoal (o guia), desde que haja deslocamento voluntário com finalidade recreativa. Recupera-sc, assim, o conccito de "turn" ou "tour" (volta, fazer uma volta retornando ao ponto de partida), independentemente da duraçāo c da distância percorridas. Nesse sentido o projeto Vivendo a História de Campinas é um serviço turístico especializado, similar aos "city tours".

\subsection{Caráter Educativo do Turismo}

O Turismo e a Educaçāo têm estado vinculados por longo tcmpo A história do turismo moderno começa no século XVI c sua motivação principal nāo está associada ao puro lazer, conforme sugcrem nāo só os escritos da época, mas uma análise da sociedade daquele tempo. A partir do final do século XVI detecta-se um aumento nas viagens particulares, inicialmente com finalidade cducativa. Sigundo BURKART \& VEDLIK (1974:3-4), quem viajava cra a clite que "nāo teria entendido a distinção entre trabalho c lazer (já que nāo se via a si mesma trabalhando)".

A literatura inglesa da época reafirma o caráter educativo do turismo. Sir Francis Bacon, em 1612, dizia que "a viagem, nos jovens, é parte da educaçāo; nos velhos, parte da experiência" (LAVAUR, 1944:10).

A classe abastada da Europa destinava a maior parte do seu tempo ao ócio, sem que isto implicasse indolência, mas simplesmente tempo gasto em atividade nāo-produtiva:

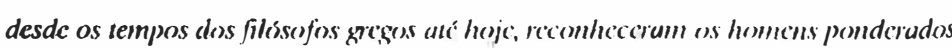

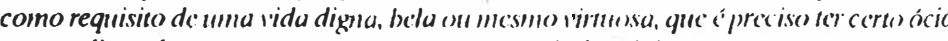
e cscar live de contato com ccitess processos industriais

quotidianas da rida. (LE:BLEN , 196,5:19)

Assim, os senhores dedicavam-se ao ócio conspícuo, cuja prova "toma a força de bens imatcriais, talentos quasc-cruditos ou quase artís ticos e conhecimentos que diretamentc não trazem vantagem à vida humana" (VEBLEN, 1965:55). A fim de acompanhar os scus amos c bem serví-los, vivia a classe dos criados domésticos em ócio vicário, isentos de trabalho produtivo. As viagens enquadravam-se nesse rol de conhecimen- tos da classe ociosa ${ }^{2}$.

Portanto tem-se, num primciro momento, uma classe que vivia no cio e viajava pelo prazer de ter mais conhecimentos, mais educaçāo. 6cio e vom o crescimento dos aglomerados urbanos, no século XIX, é que aparecerá "something like the concept of lcisurc", com o desejo de evasão da nova classe burgucsa.

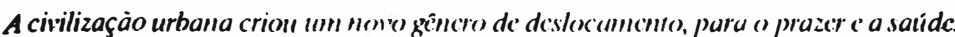
Quen quer que goze de lazeres e de uma fortuna suficiente. riaja para longe. (SCHNERB, 1969:22)

Uma atividade que começara, no sćculo XVI, com os nobres ingleses viajando para o contincnte, transformou-se, no século $X X$, quanto à motivação principal e aos protagonistas, acompanhando a

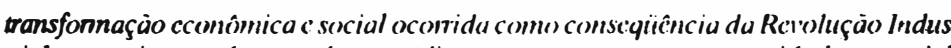
trial e o surgimento de uma classe média... com non'os gostos e neccssidades, cspecial. mente no que se refcre a férias. (ACL:RI:N7,A, 1984:\$71)

Mas se bem que a intencionalidade do turista mudou, o turismo "per si" continua a ser uma atividade educativa: conhecem-se lugares, hábitos alimentares, diferentes idiomas, espécies animais e vegutais. () aproveitamento dependerá do interesse do viajante e scrá possível na medida cm que houver uma rclação adcquada tempo/volumc. (uanto mais lugares e pessoas visitar num período de tempo, menos poderá sc aprofundar e o papel educativo diminuirá.

\section{Evolução das Práticas Pedagógicas em direção ao Lizer}

Educar ou ensinar trazem implícita a idćia de guiar, de transınitir os conhecimentos acumulados de uma detcrminada cultura. () mestre ensina e o educando aprecnde o mundo que o circunda e a história que contextualizou os seus antepassados, através de um processo de rcelabo-

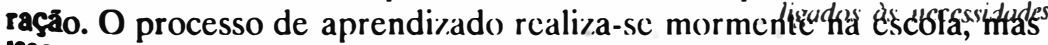
usso nem sempre foi assim. Nas socicdades ágrafas ainda existentes, a educação dos novos membros acontece pela transmissío oral dos usos, técnicas e costumes do grupo. Na antiguidade o ensino começa a ser ministrado em instituiçōes quase familiares:

\footnotetext{
2 Uma comedi

Que comédia ale mã satiriza, inclusıve. cssa rclacão: "Viajamos de pai para fillhc, sem que nenhum fazcr nos impcça" (I.AVAUR. 1974:20).
} 


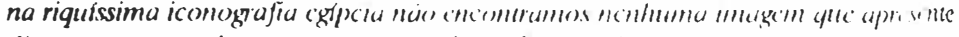

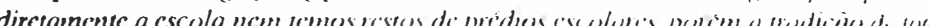

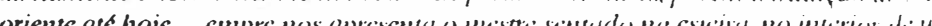

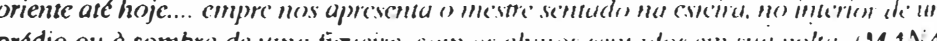
CORDA, 1989:19)

Na Grécia, no início do sćculo V a. ('. existia a Grámmata (escola de letras).progenitora direta da atual. No século 1228 d.C. ć apresentado um programa muito similar ao aplicado atualmente e, no século XVI, a Ratio Studionum regulamenta o sistema escolástico jesuítico com a (irganização em classes, horários, programas c disciplinas da forma que hoje é aplicado pela escola tradicional.

Paralelamente, desde a mais remota antiguidade pode-se resgatar pensadores que tentaram mudar os mćtodos, para começar aqueles que sentavam debaixo da figueira. O próprio Aristótcles ensinava passeando pelos parques. Platāo refere-se à aplicaçāo de jogos para aprender cálculo. Campanella propõe, cm 1606, uma cscola onde "os cidadāos ensinam os costumes e as histórias pintadas nas paredes da cidade, de modo que as crianças aprendam-nas scm enfado, brincando" (MANAC()RDA 1989:217). Rousseau, no século XVIII, propōe a redescoberta da cducaçāo dos sentidos e a experiéncia dircta das coisas, a educaçāo da consciência. No século XIX, J. Henri Pestalorzi dì que "se deve ensinar mais com a ajuda do objeto do que palavras" (MANAC'()RDA, 1989:264).

A partir de 1875 a psicologia torna-sc uma aliada imprescindível do ensino. Surge no início do século a Escola Nova, entre outros com ()live Décroly. Com ele, Maria Montessori desenvolve sua teoria dos centros de intercsse. John Dewcy, nos Estados Unidos, aplica sua tcoria do "learn by doing". Todo este movimento levará a uma revoluçào no ensino, seguida na América Latina por Emília Ferrero e Paulo Freire. Nas últ imas décadas cada vez mais sāo utilizados equipamentos e meios de ensino informal e educaçāo contínua (fora da cscola), tais como tclevisāo, vídeo, centros comunitários, casas de cultura, muscus, estudos de meio etc (MARCELINO, 1987)

\section{4 "Site Museums" ${ }^{3}$ e Turismo}

Neste texto interessam, em especial, a pedagogia atravćs dos museus e a educaçāo pelo lazer atravćs do turismo. Fundamentada princi-

3 Um "site museum". segundo definiça da ICOM . "International (onncil of Museum (órgåo da UNES(C). sediado cm Paris). é um muscu concelido c instalado para proteger a propriedade original on scja prescrvado no local ondc cisa propricdade

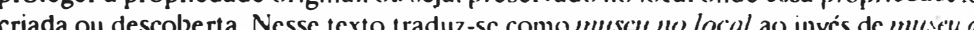
sfíio porque este segundo termo limita o conccito a sítio arqueológico. palmente na teoria do "learn by doing" a partir da década de 1970, a educação nos muscus consolida-se na Europa. ()s muscus de ciência permitem a experimentaçāo, os muscus de arte as experiências sensoriais abrangentes.

O ensino da História através de muscus tcm possibilidades de combinação com outras esferas de atividade. No Muscu Histórico Municipal de Munique, os estudantes podem usar roupas de ćpoca e fazer teatro inspirados na exposição. ()utra modalidade adotada nos paísés do primeiro mundo é o ensino da História através dos chamados "site museums" ou seja, muscus no local. A idćia não ć mais trasladar os objetos para um prédio no centro da cidade, mas sim levar o usuário a ver sítios arqueológicos, granjas, castclos ctc, ao vivo, na sua totil dimensāo com pessoas vestidas a caráter ou figuras de tamanho nat ural, recriando cenas do cotidiano. E nesta nova modalidade que reaparece com toda força a importância do turismo como fator pedagógico.

Os "site muscums" utilizam-se tanto de equipamentos turísticos (hotéis, transporte) como de serviços de apoio. Criados com finalidade cultural, transformaram-se num recurso turístico contemporânco c: em muitos casos, comercial. Há autores, inclusive, que já estāo analisando de forma crítica esta indústria da herançás são os recriados, como o caso de Skansen, na Suécia, e os originais, com lronbridge (iorge na Inglaterra, que atraem milhōes de turistas 0 ano.

\section{TURISMO COMO ALTERNATIVA DE ENSIN() DE HISTCORIA: Projeto "Vivendo a História de Campinas"}

A proposta básica para o desenvolvimento do projeto "Vivendo a História de Campinas" foi a utilização do Turismo como um instrumento

- O Centro Georges Pompidou em Parris. por cxemplo. tcm esculluras comcstiveis S HEWISON (1987). no seu livro A inchistriu da hicranç̧a. dir quc hoje na inglaterra está-se cemana, transformando o pais intciro num erandc consumir o produto $A$ pais intiro num grande mincli e levando os tiristas a

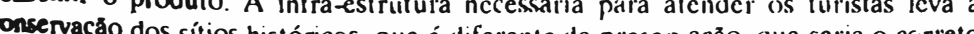
do ponto de vista históricos. que é diferentc da prescivação. que serla o ccirreto diferente de vista histórico. (oniscren'ar significa descontevtualizar para dar um uso HUDSO enquanto prescenar significa manter o contcxto histórico. (Ver também UDSON. 1987 e CRESP() 
pedagógico para o ensino da História, ampliando a visá() de um "city iour" para entretenimento.

\subsection{Origem e Proposta}

O material utilizado começou na verdade a ser pesquisado $\mathrm{em} 1982$ quando se realizou um levantamento da arte da cidade. Este trabalho foi ampliado nos anos subseqüentes c, em 198.5, aprescntou-sc um projeto de Turismo Receptivo (ultural em (ampinas, considerando que (jualquer proposta de turismo na cidade deveria passar, necessariamente, pela oferta cultural, ${ }^{6}$ já que Campinas nāo tem reçursos naturais de grande expressão. Um interesse pessoal na História levou a uma ampliação desse aspecto da cultura da cidade.

Comparando fotos ou lendo a história, percebeu-se o pouco que restou desta. Ruas transformadas em avenidas levaram consigo pedaço de prédios inteiros; o outrora luxuoso teatro dera lugar e um estacionamento e depois um calçadāo. Inverteu-sc, entāo, a metodologia: em lugar de partir da cronologia oficial, que levava a grandes vazios no espaço geográfico, passou-se a procurar o passado daquilo que havia restado em forma de monumentos, prédios ou praças.

A pergunta nāo foi onde está determinado marco, mas porque esta rua existente leva este nome? Este clube que está aqui, quando começou? Este chafariz, como veio parar aqui? - Partindo de meia dúzia de sobrados, de algumas dezenas de monumentos, foram-se descobrindo mais coisas dia após dia, procurando nos arquivos do (entro de Memória da Unicamp, na Prefeitura, conversando com pessoas idosas, com historiadores, velhos fotógrafos, todos aqueles que podiam sanar de alguma forma a falta de material sobre a cidade. Conseguiu-se assim informaçāo que não consta nos livros oficiais, como dados do cotidiano, a "peti histoire" ${ }^{\prime 8}$.

Paralelamente, estudos no campo da educação levaram a perceber a importância de se aplicar novos métodos de ensino, dando aos cstudantes a possibilidade de vivência, de contato com o objeto. Propôs-se contar de forma amena, durante um passcio, o que tinha sido "descoberto" en anos de pesquisa. Surgiu, assim, o projeto Vilvendo a Histónia de Campinas".

6 O projeto chamou-se Campinas commo Pólo (ultural c ganhou o primeiro prémio Convention and Visitor Burcau. cm maio de 1992

7 Disciplina crucial ao futuro de homem. porque é a única capaz de cxplicar o presente dar exemplos para o futuro.

8 Linha que privilegia os dados do cotidiano do povo $\mathrm{cm}$ lugar dos fcilos dos grandes vultos.

9 Na ocasiåo, o projeto teve o apoio da PUCAMP - Pontificicia Ĺniversidade Católica de Campinas, contando com a infra-est rutura do Muscu da Liniversidade e sendo parte de um programa mais amplo de apoio ao cnsino formal.

\section{Objetivos e Aplicação}

O projeto Vivendo a História de Campinas teve por objetivo dar aos tudantes a possibilidade de aprender História de uma forma lúdica, mediante objetos concretos, na linha da educaçáo ativa c da pedagogia mes museus. Propôs uma vivência, um passcio no qual sc visitavam monumentos, prédios c locais onde aconteceram falos significativos, ao mesmo tempo em que se tentava reviver, através de relatos, o cotidiano da sociedade da época correspondente.

Essa idéia foi aceita por professores de cscolas públicas c algumas particulares que adotavam métodos nāo-tradicionais, c aplicado experimentalmente junto a estudantes do primeiro e segundo grius.

Chegou-se, portanto, ao ensino de História percorrendo os lugares em que a mesma aconteceu, nurna viagem imaginária a um passado de quase 300 anos, onde fechava-se os olhos fazcndo "dc conta" que o trânsito era substituído pela mata. Andava-se pelas primciras ruas da cidade, parava-se nos monumentos daqueies quc a fizeram, cntrava-sc nos poucos prédios miraculosamente salvos do "progresso", contando as histórias da História, colocando no toca-fitas as músicas da ćpoca, discutindo com os estudantes as mudanças culturais c a industrialização recentes.

Como resultado obteve-se uma grande demanda por parte das terceiras séries do primero grau, que tinham Município no scu programa, e por parte de professores de História e Gcografia do scigundo grau. $\mathrm{O}$ passeio didático também foi solicitado por entidades particulares, como, por exemplo, Núcleos de Idosos, cujas pessoas puderam acrescentar inclusive informaçōes da própria experiência. Estudantes dos cursos noturnos tidos como "turmas difíceis" demonstraram um interesse sem precedentes, conforme depoimento dos professores. A tônical dos passeios era que os estudantes não queriam que acabasse, demonstrando o sucesso da proposta.

Outro resultado importante foi a mudança acontccida no conceito de monumento entre o início c ofim do "tour". (Os monumentos, através do conto, eram transformados $\mathrm{cm}$ pessoas concrctas $\mathrm{c}$ passaram a ter uma dimensão diferente, merecendo outrotratamento, mais familiar c portanto de respeito ${ }^{10}$. A apreciaçāo da música também apresentou mudanças. Ao primeiro choque com a música crudita do século XIX que provocava risos e chacota, seguia-se uma curiosidade c finalmente um real interesse, ao ponto de estudantes de periferia solicitarem ouvir uma ópera inteira.

10 O que nåo se conhece, se desrespeita mais facilmente 
Isto dá a medida do envolvimento efelivo conscguido com um "pass rado total" cultural e nāo apenas com fragnne'ntos matériais.

\section{CONCLUSÃO}

Desde o início houve ciência de que a proposta náo correspondia ao modelo de democratizaçào do ensino, que propóc uma discussáo c ntre alunos e professores em plano de igualdade, e tampouco de populariza. çāo do turismo, que pressupõe tornar o mesmo acessível às camadas desfavoráveis economicamente. Dependendo do modelo adotado pela instituiçāo educacional, pode transformar-se numa proposta autoritária, na qual o professor fala c os alunos escutam. Por outro lado, se nāo há condiçōes de patrocínio, o projeto só pode ser aplicado por instituiçōes pagas, ou seja, escolas particulares, transformando-se assim em turismo de classes privilegiadas ou da burguesia (ARRILLA(jA, 1976:120)-1)

Apesar dessas limitaçōes, entende-se que a proposta é válida, porque, mesmo que o estudante permaneça mudo, ele poderá fazer a sua leitura do objeto histórico e esse contato direto com a cidade estará contribuindo grandemente para a formaçāo da sua consciência social. A limitaçāo econômica nāo é exclusiva desse projeto, faz parte de um contexto social mais amplo e, pelo menos, se alguns membros das classes mais abastadas adquirem determinada consciência social, pode-se ter uma esperança nos cidadāos do porvir.

Acredita-se que esse projeto tem grande potencial $\mathrm{em}$ cidade históricas, mas nāo é exclusivo delas; mesmo naquelas que têm descuidado seu patrimônio sempre haverá uma rua pela qual passaram os primeiros habitantes, sempre um monumento, uma praça ou mesmo um espaço vazio onde possa ser recriado o cotidiano do povo protagonista.

A inovaçāo do trabalho está na inserçāo do conceito de cidadania. De acordo com SAVIANI (1986) cidadāo quer dìer habitante da cidade, mas um habitar que implica participar ativamente, significa ser sujeito de direitos e deveres, ter uma consciência cívica que nāo ć possível sem dominar o saber sistematizado da sociedade. C.onforme observa L()VISOLO (1989:17) "a formaçāo do cidadāo é trabalhada pela pedagogia moderna através da formaçāo da consciência histórica c cívica", ou scja a formaçāo do cidadāo passa pelo aprendizado da história.

A memória histórica cé a âncora que possibilita que, dliante do turbilhüo da mulança

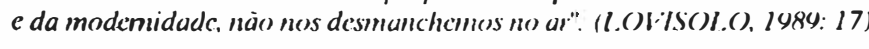

Para ser um cidadāo e participar da vida de uma cidade é preciso primeiro conhecê-la e valorizá-la; resgat ando o elemento subjetivo, amála. Isso pode ser conseguido através de uma abordagem efetiva que substitua a racional, conforme propunha o museólogo Marcel Evrard na década de 1970

HALBWACHS (1968) estabelece uma diferença entre memória coletiva e memória histórica, alegando que a segunda se coloca acima dos grupos e a primeira pressupōe uma inserçāo. Tem-se a convicçāo de que, levando os estudantes, fundamentalmente as crianças, a conhecerem a História da sua Cidade de uma forma participativa, propiciando a experiência mediante um "tour", pode-se conseguir essa inserçāo na comunidade que transforma a memória histórica em consciência social.

\section{REFERENCLAS BIBLIOGRÁFICAS}

ACERENZ.A, M. A, 1984. Administración del turismo - Conceptuación y organización. México: Trillas, v.1.

ARRILAGA, J. I. de. 1976. Introduçüo ao estudo do turisimo. Rio de Janciro: Rio. BAKUNIN, M. 1979. La instricción integral. Iispaña: Siglo XXI.

BURKART. A. \& MEIDLIK. S. 1984. Tourism: past, prescent and futurc. I ondon: Heincmann.

CRESPO TORAL. H. 1985. Muscos. arquelogía. arquitectura y cstética. In: ()I :A. Alternativas de educación para gmipos culturalmente diferenciades. ('ucnca: ()I : A

FERNANDEZ. FUSTER. L. 1974. Teorra r recnica del nurismo. Madrid: Nacional. HALBWACHS. M. 1968. La mémoire collectire. Paris: Pressc Linivcrsitairc Irançaisc. HEWISON, R. 1987. The heritage industn: London: Mcthucn Paperbacks.

HEWISON, R. 1987. The heritage industn. London: Methucn Papert
HUDSON, K. 1987. Museums of influence. Cambridge: Univ. Press.

LAVAUR, L. 1944. El turismo en su historia. Barcclona: I'd. Tu rísticas.

LOVISOLO, H. 1989. A memória c a formação dos homens. Reırista de Estudos Histúricos. Rio de Janeiro. v.2. n.3, p.16-28.

MANACORDA, M.A. 1989. História da edécuçào. Såo Paulo: Corter/ Autores Associados. MARCELINO, N. C. 1987. Lazer c cdiccaçüo. Campinas: Papirus.

SAVIANI. D. 1986. Educação. cidadania e transição democrática. In: COVRI:. M. L. A

cídodania que nào temos. Sảo Paulo: Brasilicnsc.
SCHNERB, R. 1969.

HERB, R. 1969. O século XIX. o apogeu da civilização européia. In: CROUZET, M.

Hišrória geral das civilizaçōcs. São Paulo: Difusão Européia do L Livro.

VEBLEN. T. 1965. Teoria da classc ociosa. São Paulo: Pioneira. 